\title{
A Study on Interpreting Teaching Activities Based on the Flipped Classroom Model
}

\author{
Yun Li \\ Kunming University, Kunming, Yunnan, China
}

Keywords: Flipped Classroom, Interpreting Teaching, Action Research on Moodle.

\begin{abstract}
This thesis aims to conduct action research on current problems existing in interpreting teaching via Moodle teaching platform in three aspects, namely interpreting skills training, teaching modes, interpreting learning modes and evaluation mechanism of interpreting performance. This thesis, through in-class observation, questionnaires, interviews with students and students' self-evaluation, finds that flipped classroom teaching can improve the performance of interpreting training, while Moodle teaching platform promotes flipped classroom teaching practices.
\end{abstract}

\section{Introduction}

Recently, the idea of flipped classroom has attracted the attention of domestic and foreign experts and scholars. Many scholars overseas have conducted researches on the combination of flipped classrooms and various courses [1]. It was agreed that the idea of flipped classroom was first formally brought up by Jonathan Bergmann and Aaron Sams, the two chemistry teachers from Woodland Park High School in Rocky Mountains, Colorado, US. [6]

The current situation indicates that the "Flipped Classroom" teaching mode is a necessary trend. However, there is no fixed mode as to what to "be flipped" and what to be held on to. A lot of questions remain to be discussed. Du Yue, Yang Gang, Yang Wenzheng and Chen Li have conducted a comparative analysis between different flipped classroom cases abroad. They pointed out that Khan Academy started by Salman Khan, an American practitioner of technological education, is a typical case of flipped classroom[4] [8]. However, there is not yet a consensus on what is a flipped classroom, even on whether to call it a flipped classroom. Some call it a flipped classroom, while others adopt the name of "reversed classroom" or "inverted classroom". Zhong Xiaoliu, Song Shuqiang and Jiao Lizhen believe that a "flipped classroom refers to a new teaching mode that requires teachers to provide learning resources, mainly in the form of videos before class under an information environment. Students should watch and study the teaching videos and other learning resources before class. Then, teachers and students will complete activities such as answering questions in homework, cooperating to explore problems as well as interaction and communication in class together"[7].

It can be easily seen that the idea of flipped classroom does not simply refer to the order reversing of curricular and extracurricular studies, but a new teaching mode that promotes students to perform knowledge construction through self-study, inquiry-based learning as well as interaction and collaboration among students and between teachers and students. In China, flipped classroom practices are in larger scale and exert greater influence in high schools, but there are few studies on the combination of flipped classroom and interpreting teaching.

\section{Enlightenment of Flipped Classroom to Interpreting Teaching}

Some experts have pointed out that interpreting teaching had to take into account the characteristics of schools and districts. Liu Heping appealed all colleges and universities to consider local features, cultivating localized interpreting talents who can serve local economy [5] 
However, a lot of universities in China are still limited in terms of undergraduate interpreting teaching in many aspects. First, interpreting teaching time is in severe shortage. Many schools only have 2 to 3 class hours of consecutive interpreting classes every week. Besides, most classes have 20 to 30 students, which are too big, not to mention classes of 40 to 60 . Under these circumstances, qualified interpreters are hard to cultivate in undergraduate phase [2]. Furthermore, becoming an interpreter requires an accumulation of a large amount of knowledge of all subjects, keeping up with current affairs, good mental state and professionalism, and therefore the consciousness of lifelong learning and such learning ability as an urgent issue should be cultivated. Finally, students' cognition of learning should change. It should guarantee that they will make full use of extracurricular time to improve their learning abilities.

At the beginning of the first semester in 2014, the author has carried out a questionnaire survey among the English majors of translating and interpreting modules in the 2011 grade of the author's school. It was found that over $85 \%$ of students prefer learning through the internet, over $95 \%$ of students enjoy internet searching and cannot study without computers and the internet, over $70 \%$ of students are willing to use online classes and Moodle platform, over $80 \%$ of students prefer opportunities to present themselves in class instead of listening to the teacher for an entire lesson, and over $70 \%$ of students like interaction and communication and are willing to try the learning mode of "learning through doing". Students of the post-90 generation taught by the author mostly have a good concept of electronic technology, are familiar with voice and video recording software on computers or cellphones and can complete interpreting work with the help of modern education technology.

In this context, bringing the idea of "flipped classroom" into interpreting teaching conforms to not only the current situation of interpreting teaching, but also students' actual needs. Dan Berrett put forward that flipped classroom helped students learn how to think and teachers discover difficulties occurring in students' learning process so that they could provide necessary assistance [1]. Eric Mazur from Harvard University pointed out that the core of teaching was not to simply passing on knowledge, but to help students absorb knowledge [3] (quote from a secondary source, Dan Berrett, 2012). The author put the characteristics of interpreting teaching, high request of skills and immediacy into consideration, conducted flipped classroom teaching via Moodle platform, aiming to change the traditional interpreting class training mode, that is, teacher elaborate interpreting skills and students receive passively. Through Moodle platform, interpreting practices can happen along the teaching, both inside and outside of class, thus realizing "learning through interpreting" and "interpreting while learning".

\section{Action Research on Flipped Classroom Interpreting Teaching}

Action Plan Design. The interpreting teaching team of the author discovers through reflections on previous interpreting teaching experiences that, the teaching time is of great deficiency, training methods are of low efficiency, students are of low momentum and interpreting learning cannot match the market's need. To solve the problems above and the following changes in teaching were decided. First, the skill learning mode led by teachers was replaced by interpreting skills learning mode referring to students' cognitive level; second, the single interpreting training mode of "teacher elaborating skills in class" and "students practicing in class" was replaced by a mixed-mode study, including "learning systematic skills before class", "instant in-class interpreting performance assessment" and "real interpreting practices after class"; third, the evaluation method centering on interpreting teaching was replaced by a systematic evaluating mechanism of interpreting talents, including evaluation of "interpreting skills, real interpreting abilities and social service".

Implementation of Action Plan. The specific steps of carrying out the interpreting teaching action plan based on teachers' guidance, centering on students' action, with the idea of flipped classroom and through Moodle platform are as follows:

Construction of Interpreting Skills Training Mode Based on Flipped Classroom. The author tried to know students' cognitive levels through interpreting tests, questionnaires and case interviews, according to the results of which conducted module integration and adopted interpreting skill training modes based on flipped class. From improving students' listening skills, interpreting skill training 
will gradually cultivate other skills including short-term memory, bilingual transference, note-taking skills and comprehensive interpreting skills with the training of public speaking skills all along.

Take short-term memory skill as an example, in flipped classroom teaching, students realize the effective integration of learning, absorbing and automation of interpreting ability through study before class, training in class as well as broadening and deepening study after class. Before class, content concerning short-term memory skills will be put into PPT and short videos which will be uploaded onto Moodle platform a week before class for pre-class study, accompanied by some practices of short-term memory. During class, students have to conclude short-term memory skills, followed by training of summarizing, concluding and repeating after listening to test and strengthen students' short-term memory. After class, practices to strengthen skills and broaden the scope of learning will be conducted. For example, students can listen to news on current affairs or watch TED videos and do practices of repeating and summarizing, etc.

Construction of Mixed-mode Study Based on Moodle Platform. Moodle platform and mixed-mode study, with a combination of face-to-face communication and internet interaction, break the time boundary between in-class teaching and after class practices of traditional teaching method, construct a rotational and continuous interpreting training mode including "interpreting skills study before class", "interpreting practices and performance assessment in class" and "interpreting practices and real interpreting work after class". For example, students can learn interpreting skills before class, conduct instant interpreting training and further discussion of interpreting skills in class, thus turning interpreting class to interpreting spot, and simulating or doing real interpreting work after class. In this way, students can turn interpreting skills into interpreting ability.

Take business interpreting flipped classroom as an example, the total teaching time for one semester is 32 class hours, but the time spent on flipped study before class and interpreting practices after class is almost two times of the time spent in class. The interpreting training mode of "interpreting skills+business topics" based on flipped classroom can be seen in the following chart.

\begin{tabular}{|l|l|l|}
\hline $\begin{array}{l}\text { Interpreting skills + business } \\
\text { topics }\end{array}$ & Training target & class period \\
\hline $\begin{array}{l}\text { Speech skills + business etiquette } \\
\text { speech }\end{array}$ & $\begin{array}{l}\text { Develop students' oral skills } \\
\text { through oral presentations }\end{array}$ & $\begin{array}{l}\text { Skill learning before class 2+ } \\
\text { Classroom interpreting training } \\
4+ \\
\text { After class simulation } 4\end{array}$ \\
\hline $\begin{array}{l}\text { Listening for interpreting + } \\
\text { international events }\end{array}$ & $\begin{array}{l}\text { Through the association, } \\
\text { prediction, segmentation, } \\
\text { summary, logical reconstruction to } \\
\text { improve listening ability. }\end{array}$ & $\begin{array}{l}\text { Skill learning before class 2+ } \\
\text { Classroom interpreting training } \\
\text { 4+ } \\
\text { After class simulation 4 }\end{array}$ \\
\hline $\begin{array}{l}\text { Short time memory } \\
+ \text { communication and negotiation }\end{array}$ & $\begin{array}{l}\text { Through the shadow practice, } \\
\text { retelling, summarizing to improve } \\
\text { the ability of short-term memory }\end{array}$ & $\begin{array}{l}\text { Skill learning before class } 4+ \\
\text { Classroom interpreting training } \\
\text { 6+ } \\
\text { After class combat simulation } 6\end{array}$ \\
\hline
\end{tabular}

\section{Effect and Reflections of Interpreting Training Based on "Flipped Class"}

The author tried to know the effects of flipped classroom through observation in class, questionnaire survey and case interviews, finding that students are gradually getting used to flipped classroom teaching.

First, through observation in class, it has been found that most students were having class without pressure, turning from "passive training" to "positively asking questions". Most interpreting skills have been put into PPT, micro lectures or videos which will be uploaded onto the online class platform or QQ group for pre-class study. Class time is used to show the outcome of interpreting skills training and in-class random interpreting training. The instant interpreting training randomly added by teachers into class activities can help create a sense of pressure, so that students will not become absent-minded. 
Second, the author tried to know the implementation effects of the idea of flipped classroom and Moodle platform through questionnaires. For instance, at the end of the semester in spring 2014, the author has conducted questionnaire survey among 83 students of translating and interpreting modules, and collected 81 questionnaires, 79 of which are valid. Later, according to the results of the questionnaires, 12 students were randomly chosen to conduct follow-up interviews to know about the deeper reasoning behind statistics of questionnaire results. This questionnaire adopts Likert Scale. The five options are as follows: totally agree, agree, don't care, disagree and totally disagree. The questionnaire consists of three parts. The first part is basic information. The second part is closed questionnaire, consisting of seven parts. The third part includes open-ended questions. The second part consists of the following sections. First, flipped classroom has a better effect than traditional interpreting training mode. Second, interpreting skill training based on flipped classroom is more effective than previous interpreting skills elaboration. Third, interpreting skills training based on flipped classroom can help improve interpreting ability. Forth, Moodle teaching platform helps with increasing interests in learning interpreting. Fifth, Moodle teaching platform based on flipped classroom is beneficial to cultivating the ability of self-study. Sixth, Moodle teaching platform is helpful to learn interpreting. Seventh, evaluation method based on learning process is more effective than summative evaluation method, which means that evaluation based on learning process will cover $100 \%$ of the overall result. The open-ended question of the third part is "which module is the most popular one among the six modules on Moodle platform and why?" The six modules are interpreting learning and reflections, interactions and communications, interpreting skills training outcome demonstration, interpreting teaching plans and courseware, interpreting resources extension and in-class instant interpreting sharing.

The results of the closed questionnaire are as follows: (1) In general, students recognize the teaching mode of flipped classroom. 82\% of the students think that flipped classroom interpreting teaching is more effective than traditional interpreting training mode. Students' initiatives of learning can be better reflected in flipped classroom, helping students turning from passive to active. (2) 88\% of the students believe that learning interpreting skills by themselves in the extracurricular time and demonstrating interpreting training outcome in class are more effective than the traditional way of elaborating interpreting skills in class. In-class interpreting performance show can not only enhance students' confidence but also increase interest in learning interpreting. (3) $100 \%$ of the students believe that interpreting skills training based on flipped classroom can help improve interpreting ability. By increasing pre-class interpreting skills learning and post-class interpreting extension training, the intensity of interpreting training can be enhanced, which is helpful to improve students' interpreting ability. (4) Only 35\% of the students agree that flipped classroom helps with learning interest increase. We can see that learning interest is influenced by a variety of factors. In class, teachers should act as "advisors" who offer "guidance", inspiring students to explore according to their interests. (5) $65 \%$ of the students believe that Moodle teaching platform based on flipped classroom helps students to develop self-learning ability. Uploading interpreting tasks, communicating and interacting, sharing interpreting resources via Moodle platform can help students cultivate their ability of self-study and self-supervision as well as enhance interaction and cooperation among students.(6) Only 53\% of the students think that Moodle teaching platform is helpful to interpreting learning, indicating that Moodle, as a teaching platform, can promote teaching, but not automatically promote students to study or replace the teachers' role of "teaching" and students' role of "learning".

The third part of the open-ended questions involves the influences of the six major sections of Moodle platform over students. The most popular modules are interpreting skills training outcome demonstration (88\%) and interpreting resources extension (87\%), followed by interactions and communications (71\%), in-class instant interpreting sharing (51\%), and interpreting teaching plans and courseware (47\%). Students' questionnaires reflect that $88 \%$ of students prefer opportunities to show themselves, $71 \%$ of students like interaction and communication and $87 \%$ of students recognize the help of interpreting resources extension. The main reason for the popularity of the last part is that, it provides not only the outlines and requirements of various interpreting accreditation tests in China, 
but also a large amount of interpreting learning resources for students to train by themselves. Naturally, this part is very popular among the students. 51\% of students like the instant sharing of interpreting tasks in class. This percentage is not high. It has been found through case interviews that students prefer face-to-face instant comments rather than comments in this module, which always have a delay. Only $47 \%$ of students like the part of interpreting courseware. That is because this module is less interactive. Students can only accept information passively with no opportunities to express themselves.

Again, the author conducted a follow-up interview with 12 students on the effect of flipped classroom and Moodle platform, finding that: (1) 9 students believe that flipped classroom can help extend the time of learning interpreting, promote the effective use of extracurricular time, cultivate self-study awareness and improve the efficiency of interpreting learning; 2 students clearly indicate that flipped classroom can help correct their learning attitude, and a large number of demonstrations of learning outcomes help enhance their confidence; 4 students think that flipped classroom does not add additional pressure to them, but makes pre-class preview more efficient; 3 other students propose that asking more students for advice on how to conduct flipped classroom teaching will deliver better results. (2) As for the effects of Moodle platform, 10 students think that the Moodle platform can promote resource sharing, learning interaction and teaching feedback, increase interactions among students and between teachers and students, ensure that every student has the opportunity to show their learning outcomes and receive direct guidance from teachers. (3) As for the effect of cooperative learning and self-learning based on flipped classroom, 7 students think cooperative study is effective, while 5 students believe the efficiency of self-study is higher, because in cooperative study, work distribution among group members may not be reasonable and assessments are difficult to be fair; however, 9 students think pair work will have better effects.

Finally, for three consecutive years, students' online teaching performance evaluation of the interpreting course that the author has been teaching has grades of over 95 (full mark is 100), which is among the top $15 \%$ of all teachers in Foreign Language College. The evaluation grades and feedback can indicate students' recognition of interpreting flipped classroom teaching to some degree. Representative comments from students are as follows:

Comment two: Teacher encourages us to take part in the interpreting evaluation exams, which makes me feel more motivated because there is a goal for my study. I am so glad that I have passed the mid-level interpreting accreditation test and the written part of high-level interpreting accreditation test, but a little bit regretful that I didn't pass the oral one. Now, I know where I should be working hard and I will definitely participate in that exam again.

Comment three: What I like most this semester is the part that teacher let us perform mock interpreting. The mock interview and press conference of our group is awesome. We are confident to improve.

Comment four: Uploading interpreting tasks through sharing and communication on Moodle platform is so effective. I have learned a lot of interpreting skills and shared many interpreting training recordings in this semester.

Through the comprehensive analysis of in-class observation, questionnaire survey, student interviews and student feedback, the author can conclude the following: First, the classified and step-up interpreting training mode, which conforms to the law of cognitive development, is closer to students' actual needs and reflects the step-by-step characteristic of study. Module integration of interpreting skills can highlight the internal link and systematicness of interpreting skills. So teaching according to integrated modules will have better effects than teaching according to sections of tradition interpreting teaching materials. Second, Moodle interpreting teaching platform can effectively promote flipped classroom teaching, break the time and space limits of traditional interpreting study, and extend interpreting study from curricular to extracurricular and from online to offline. In this way, traditional single face-to-face communication will be transferred to diversified interactive communication and instant communication, which have similar advantages to face-to-face communication and internet communication that have no limit and barriers. Third, the interpreting talent evaluation mechanism, including interpreting skills, interpreting ability and social service 
combines in-class interpreting learning with social service and evaluates students' interpreting ability in an all-around way, which is beneficial to evaluate students' ability of interpreting, learning and performing social service.

\section{Conclusions}

This thesis, based on the idea of flipped classroom teaching, conducts action research over interpreting skills training through Moodle teaching platform. The classified and step-up interpreting training mode which conforms to the law of cognitive development is conducted. Mixed-mode interpreting study, which is designed according to characteristics of the post-90 generation, based on internet interactions in combination with face-to-face communication, is adopted. The "trinity" interpreting evaluation mechanism integrating "interpreting skills, interpreting ability and social service" is used. Flipped classroom practice is conducted in the teaching sessions of interpreting skills training, students' learning methods and evaluation methods respectively so as to improve students' interpreting learning outcome, optimize study methods, highlight the aims of interpreting evaluation. In general, interpreting training mode based on flipped classroom helps with improving interpreting training outcome. Moodle teaching platform can promote the implementation of flipped classroom teaching. However, since the research is mainly targeted at students of the author's school, the research may be representative, but still requires more extensive and deepened action researches and evidence researches to further testify the results.

\section{References}

[1] Bergmann, J., \& Sams, A. Flip Yhis Classroom: Reach Every Student in Every Class Every Day [M]. Washington, DC: International Society for Technology in Education, 2012.

[2] Chen Yanjun. Interpreting Teacher Training Seminar. "2014 Summer Training Seminar for Teachers of Translation Major in National Institutions of Higher Learning" .2014.

[3] Dan Berrett. How Flipped Classroom Can Improve the Traditional Lecture. February 19, 2012. Http: //chronicle. Comlarticle /How-flipping-the-ClassroomlI30857/

[4] Du Yue "Flipped Classroom, What to Flip and What to Hold on to, Frontline Observation of 'Flipped Classroom'" [N]. China Education News, 2014-4-9 (2006 Edition)

[5] Liu Heping, Xu Ming. Exploring the Training Model of Interpreting Talents in the Era of Globalization - A Review of the Ninth National Interpretation Conference and International Symposium [J]. Moderate Translation, 2012 (5): 53-59

[6] Zhang Jinlei, Wang Ying, Zhang Baohui. Flipped Classroom Teaching Mode Research [J]. Distance Education Journal, 2012 (4): 46-51

[7] Zhong Xiaoliu, Song Shuqiang, Jiao Lizhen. A Study on Teaching Plan Design Based on the Idea of flipped Classroom in Information Environment 2013[1]: 58-64

[8] Yang Gang, Yang Wenzheng, Chen Li. Ten Classic Cases of "Flipped Classroom" [J] Primary and Secondary Information Technology Education, 2012 (3): 11-13. 